\title{
Development of a Two-Stroke Cycle Engine for Use in the Agricultural Aviation Sector
}

\author{
Samara Herrmann ${ }^{1, *}$ (D), Macklini Dalla Nora ${ }^{1}$ (D), Thompson Diordinis Metzka Lanzanova1 (iD) \\ 1.Universidade Federal de Santa Maria - Grupo de Pesquisa em Motores, Combustiveis e Emissões - Santa Maria/RS, Brazil. \\ *Correspondence author: samaraherrmann@gmail.com
}

\section{ABSTRACT}

Reciprocating internal combustion engines have wide application in agricultural, recreational and experimental aircraft, resulting from their low cost and less complex maintenance compared to other engines. Thus, this work analyzed the performance of a conventional four-stroke engine operating in the two-stroke cycle by means of direct fuel injection and mechanical air supercharging. The use of a supercharger was essential in this design to provide adequate gas exchange inside the cylinder during the long valve overlap required, while direct fuel injection made it possible to reduce the short circuit of air-fuel mixture to the exhaust. Due to the double ignition frequency compared to a four-stroke engine, it was possible to obtain a large power density $(40 \mathrm{~kW} / \mathrm{L})$ at a speed of $2400 \mathrm{rpm}$, also a specific fuel consumption of $270 \mathrm{~g} / \mathrm{kWh}$ with gasoline and $400 \mathrm{~g} / \mathrm{kWh}$ with ethanol. The use of ethanol in replacement of gasoline made it possible to operate at full load (160 Nm/L) at $800 \mathrm{rpm}$ without the occurrence of knocking combustion.

Keywords: Internal combustion engine; Two-stroke cycle; Agricultural aviation.

\section{INTRODUCTION}

The agribusiness sector has great importance to Brazilian economy, representing 23.5\% of its gross domestic product (GDP) in 2017, as stated by the Brazilian Agriculture and Livestock Confederation (Reuters 2017). Changes in traditional cultivation processes, as introduction of fertilizers and pesticides, have become necessary because of the growth of agricultural production. Mhereb and Norder (2018) affirm that agricultural aviation is an essential component in the process of modernizing Brazilian agriculture and emphasize its great operational capacity. In this sense, agricultural aviation plays a key role in expanding productivity. If compared to land application, it allows the spraying of agrochemicals in a larger area in a shorter time. It also provides no contact with soil avoiding its compaction and damage to other crops; besides, it enables the application even in wet soil after heavy rainfall periods (Santos 2005).

According to data from the National Syndicate of Agricultural Aviation Companies (Parceria Agro 2019), at the beginning of 2019 the fleet of agricultural aircraft in Brazil was 2194 units, the state with the largest fleet being Mato Grosso, representing $22.5 \%$ of the total, followed by Rio Grande do Sul with 19.5\%, and São Paulo with 14.5\%. In addition, Brazil has the second largest agricultural aviation fleet in the world, only behind the United States of America, which has about 3600 agricultural aircrafts (NAAA 2019).

The Brazilian agricultural aircraft fleet is mainly composed by the model Ipanema produced by Embraer, which represents almost $60 \%$ of the total fleet. Ipanema has a Lycoming piston engine originally fueled with aviation gasoline, but it is converted to ethanol at the aircraft manufacturer in Brazil. Nevertheless, most of the engines of agricultural aircrafts operated in Brazil are

Received: Feb. 10, 2020 | Accepted: Sep. 14, 2020

Peer Review History: This is a peer reviewed version of selected paper presented at the $2^{\circ}$ Congresso Aeroespacial Brasileiro occurred in 16 -19 September of 2019 at Universidade Federal de Santa Maria, Santa Maria/RS, Brazil.

Section Editor: André Luis da Silva 
fueled with aviation gasoline (AvGas). According to Hausen (2011), all aircraft engines operating in Brazil are imported, except for those adapted from automotive engines used in experimental aviation. Imported engines increase the cost of acquisition and maintenance. On the other hand, the adaptation of automotive engines, often performed in an amateur manner, exposes the pilot and areas close to the flight region to safety-related risks. In-flight engine failure was the largest cause of serious incidents between 2008 and 2017, according to Santos et al. (2018).

Internal combustion engines are widely used in general aviation, which includes private aircraft, experimental aircraft and nonscheduled air transport. In such cases, the engine operating in the four-stroke cycle is predominant. Two-stroke internal combustion engines are widely used in ultralight aircraft and gyroplane due its simpler architecture, making them less expensive and lighter.

Homa (2013) emphasizes that two-stroke engines are not extensively used in general airplanes because they present higher fuel consumption and short-circuiting of fuel to the exhaust gases, besides lubrication and durability problems. The last two disadvantages are linked to the fact that the crankcase is used for pumping the air-fuel mixture to the cylinder.

The short circuit of the air-fuel mixture is a typical problem of two-stroke engines. Since intake and exhaust ports are positioned in front of each other in the cylinder and their opening and closing are controlled by the positioning of the piston itself, part of the new air-fuel mixture is not burned and goes directly to the exhaust, increasing the fuel consumption. In this sense, it is advantageous to use direct fuel injection in the combustion chamber, as in diesel cycle engines, so the fuel only enters the combustion chamber after the exhaust port is closed and the scavenging process is carried out with air only, solving the shortcircuiting issue. Zhang et al. (2013) has proposed the use of solenoid valves as in four-stroke engines; also, Leighton et al. (1994) and Duret and Moreau (1990) proposed low-cost injectors with compressed air assistance.

In the matter of component lubrication and durability, Sato et al. (1992), Hundleby (1990) and Nomura and Nakamura (1993) suggest the use of overhead valves and forced oil lubrication on the moving parts, as in four-stroke engines. In that way, there is no need to add lubricant oil to the mixture to achieve relatively adequate lubrication. Also, the durability problems associated with the high temperature gradient in the cylinder due to the presence of intake and exhaust ports are reduced.

With the crankcase being part of the lubrication system, an external compressor is required to pump the intake air into the cylinder, which is usually known as blower. Although the fuel short-circuiting problem is solved by direct injection, there is still the short-circuiting of air; therefore, a significant part of the intake air is directly lost to the exhaust. Hence, more compressor work is required to ensure the air supply, which consequently reduces the engine efficiency.

In relation to the fuel itself, AvGas has the addition of tetraethyllead as an antiknock agent, an extremely harmful component to the environment and toxic if ingested by humans. This additive allows an increase up to 100 in the octane number of AvGas. In this scenario, ethanol appears as a possible solution, once it is a renewable fuel with easier commercial access in Brazil, presenting an octane number around 113. Furthermore, Hausen (2011) stated that operating with ethanol reduces operational costs about US\$ 40 per flight hour.

Consequently, it stands out the lack of an aeronautical engine of national origin fueled with a more commercially accessible and less harmful to the environment fuel, which could integrate modern control systems already applied to automotive engines. Therefore, the present study explores the application of the two-stroke cycle, well known for its high power and torque density, to the modern architecture of four-stroke engines with better fuel consumption and overall durability. Ethanol was evaluated in such prototype engine in parallel to gasoline as a possible renewable substitute for the mostly used fossil fuel, considering its wide availability in Brazil.

\section{METHODOLOGY}

\section{Engine Specification}

The tests were implemented in a research engine of the Centre for Advanced Powertrain and Fuels at Brunel University, London. The engine model was a Ricardo Hydra two/four-stroke Camless, as specified in Table 1. 
Table 1. Engine Ricardo Hydra Camless data.

\begin{tabular}{cc}
\hline Number of cylinders & 1 \\
\hline Swept volume & $0.35 \mathrm{dm}^{3}$ \\
Bore & $81.6 \mathrm{~mm}$ \\
Stroke & $66.9 \mathrm{~mm}$ \\
Compression ratio & $11.8: 1$ \\
Combustion chamber & Pent roof with four valves and a central spark plug \\
Fuel injector & Magneti Marelli solenoid type with six orifices \\
Exhaust port opening & $120^{\circ}$ CA ATDC \\
Intake port opening & $130^{\circ}$ CA ATDC \\
Exhaust port closing & $230^{\circ}$ CA ATDC \\
Intake port closing & $240^{\circ}$ CA ATDC \\
\hline
\end{tabular}

Two fuels were used to conduct the experiments: European gasoline with 95 octanes that is close to aviation gasoline with 100 octanes; and anhydrous ethanol (99,9\%) with an equivalent number of octanes close to 109 . The instant of fuel injection was adjusted for a better compromise between short circuit and quality of combustion, since early injection leads to fuel loss directly to the exhaust and late injections do not provide enough time for homogenization of the mixture. In general, it was varied between $210^{\circ}$ and $270^{\circ}$ after top dead center (TDC). The ignition timing was adjusted to provide maximum torque without the occurrence of knocking, a phenomenon extremely harmful to the engine since it causes overheating and may lead internal components to failure.

The tests were performed at three specific torque values: 32, 96 and $160 \mathrm{Nm} / \mathrm{L}$. Also, the engine speed was varied between 800 and $2400 \mathrm{rpm}$ in steps of $400 \mathrm{rpm}$.

The fuel temperature near the injector was maintained at $300 \pm 5 \mathrm{~K}$. Fuel pressure near the injector was kept at $14.5 \pm 0.5 \mathrm{MPa}$.

The supercharger power consumption was calculated considering a $70 \%$ total efficiency in the compression process, which is a usual value found for roots-type blowers employed in this field.

All testing points were performed at steady state conditions and 200 consecutive engine cycles were acquired for each point evaluated after stabilizing oil and coolant temperatures.

\section{Engine Instrumentation}

The engine assembly diagram and its respective instrumentation is shown in Fig. 1. The sensors and equipment used in the instrumentation are listed below.

- Hasting HMF-200: air mass flow measurement;

- Endress + Houser Promass 83A Coriollis Effect: fuel mass flow measurement;

- Kistler 6061B: piezoelectric sensor for in-cylinder pressure measurement;

- Kistler 4007 BA20F/BA5F: piezoresistive sensor for intake and exhaust pressure measurements;

- Thermocouple type K: admission, exhaust, lubricant oil and fuel line temperature measurements;

- Ricardo rCube Unit: ignition timing, fuel injection and valve parameters control;

- Encoder LeineLinde: incremental encoder for correlation between pressure data and crankshaft angle with 720 pulses per revolution;

- National Instrumental NI US-6353 Board: data acquisition and process in real-time;

- Air compressor AVL 515: air supercharging with close loop control of pressure and temperature. 


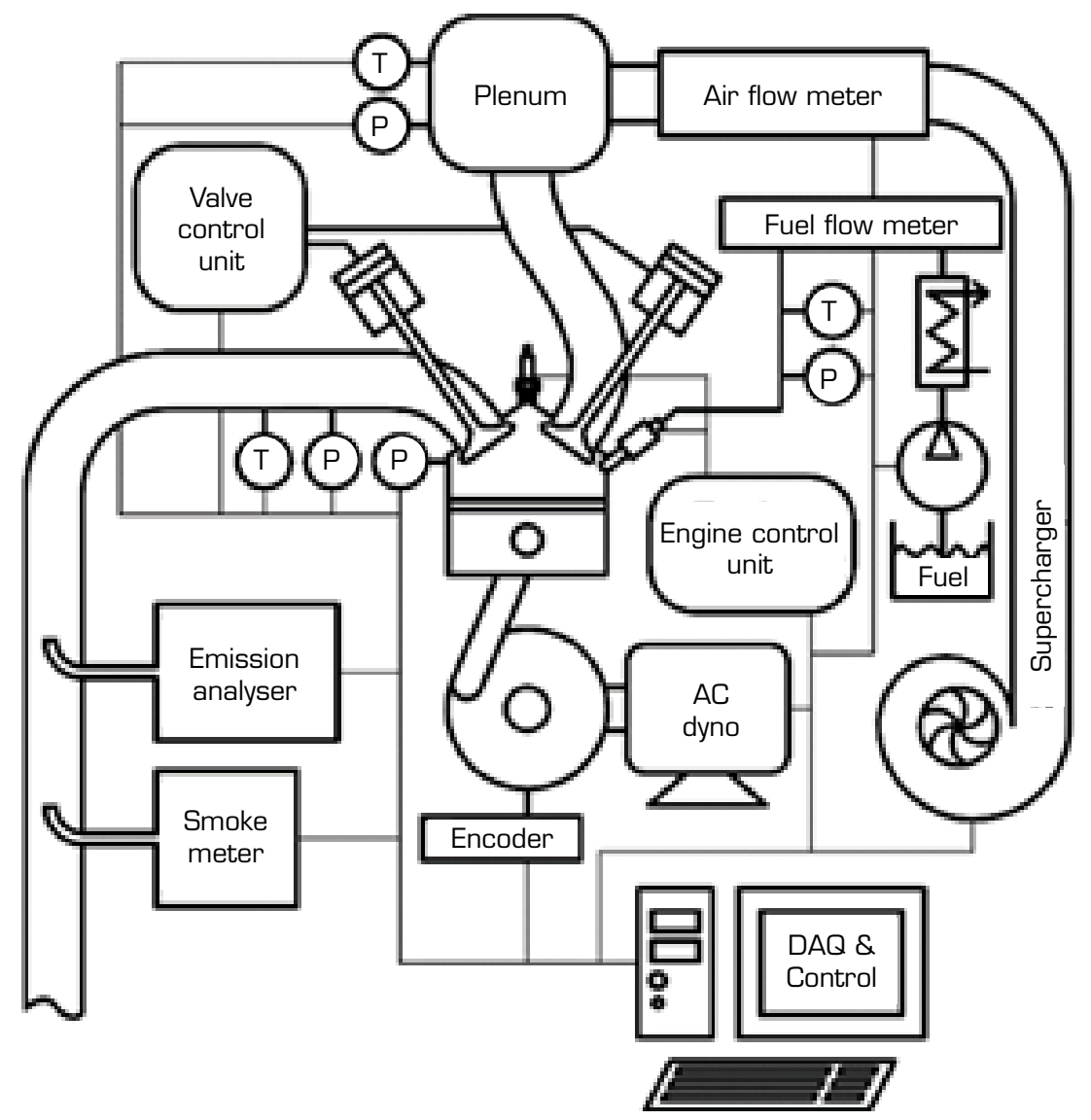

Figure 1. Engine assembly and instrumentation diagram. Source: Dalla Nora et al. (2016).

Figure 2 shows a modification made to the combustion chamber in order to reduce the problem of air short-circuiting. A mask has been added allowing the reduction of fresh air passing directly to the exhaust. More discussion on this combustion chamber feature and other design options are presented by Dalla Nora et al. (2016).

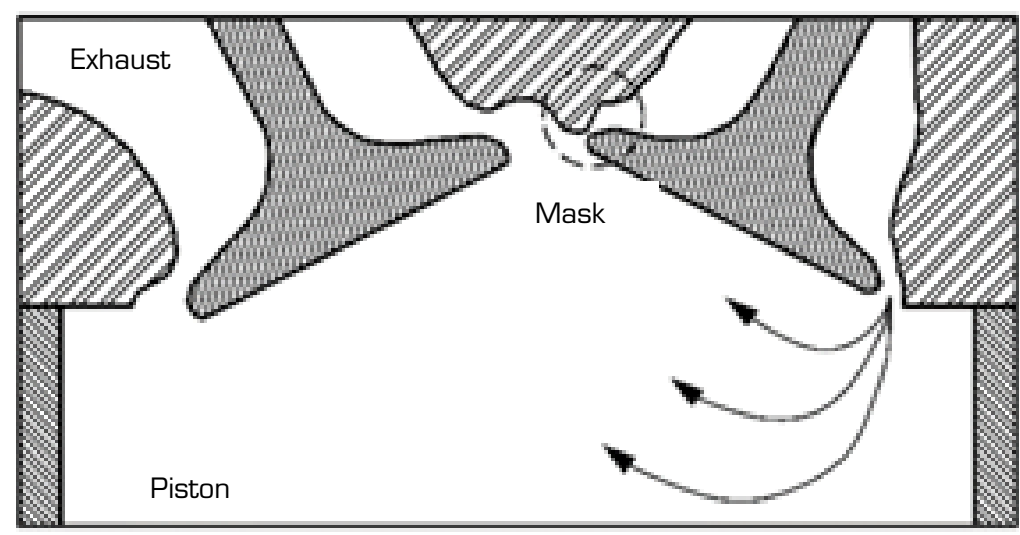

Figure 2. Combustion chamber geometry modification. Source: Dalla Nora et al. (2016). 


\section{RESULTS}

The results are presented in relation to the engine speed in rpm and its load from low ( $32 \mathrm{Nm} / \mathrm{L})$ to medium $(96 \mathrm{Nm} / \mathrm{L})$ and high load $(160 \mathrm{Nm} / \mathrm{L})$. The specific torque in $\mathrm{Nm} / \mathrm{L}$ unit reflects the expected torque of the motor according to the displaced volume. The graphs on the left show the results for gasoline, while the right shows the results for ethanol.

Figure 3 shows the indicated efficiency for different speeds with the engine fueled by gasoline and ethanol. Such parameter compares the total amount of energy supplied to the engine through the fuel to the expansion work developed inside the cylinder. The supercharger operation was also considered by evaluating the amount of power diverted from the engine to the theoretical boosting device. As expected, all curves have less amplitude when the turbocharger is operated since part of the shaft power is transferred to the compressor. Ethanol operation showed greater efficiencies, around 33\% at medium load and in the speed range between 800 and $1200 \mathrm{rpm}$. Gasoline showed greater efficiency in the same range of operation, with a value of approximately $32 \%$. The lower efficiencies are presented with the higher engine loads since the compressor consumes even more power in this condition. The lower overall efficiency of gasoline was also a result of the retarded ignition timing required to avoid knocking combustion, which was not the case of ethanol operation when the maximum torque was achieved at all times.
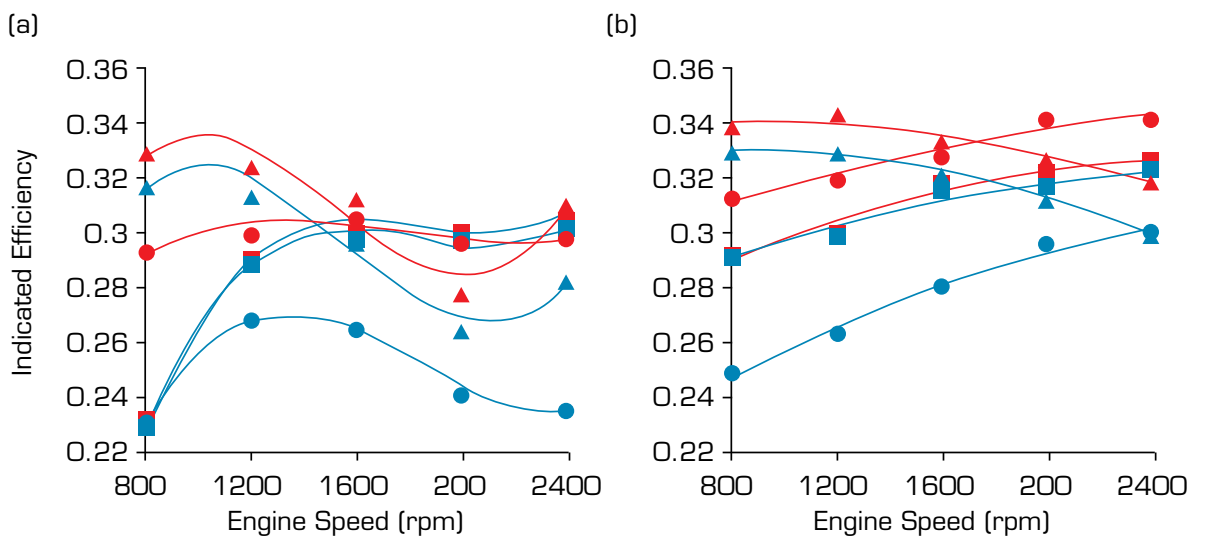
$32 \mathrm{~N} \cdot \mathrm{mL}^{-1}$ without compressor $32 \mathrm{~N} \cdot \mathrm{mL}^{-1}$ with compressor
$96 \mathrm{~N} \cdot \mathrm{mL}^{-1}$ without
compressor
4 $96 \mathrm{~N} \cdot \mathrm{mL}^{-1}$ with
compressor
$160 \mathrm{~N} \cdot \mathrm{mL}^{-1}$ without compressor
$160 \mathrm{~N} \cdot \mathrm{mL}^{-1}$ with compressor

Figure 3. Indicated efficiency for (a) gasoline and (b) ethanol.

That way, Fig. 4 presents the specific fuel consumption (ISFC). The fuel consumption increases when the compressor power requirement is increased, what is associated with efficiency reduction. Gasoline had a lower specific fuel consumption than ethanol, mainly because of the lower heating value of ethanol, approximately $64 \%$ of gasoline (27 MJ/kg versus $42 \mathrm{MJ} / \mathrm{kg}$ ). The different behavior of the $96 \mathrm{Nm} / \mathrm{L}$ operation in comparison to the 32 and $160 \mathrm{Nm} / \mathrm{L}$ conditions are attributed mainly to combustion efficiency, which is a compromise among fueling and gas-exchanging as presented by Dalla Nora et al. (2018).
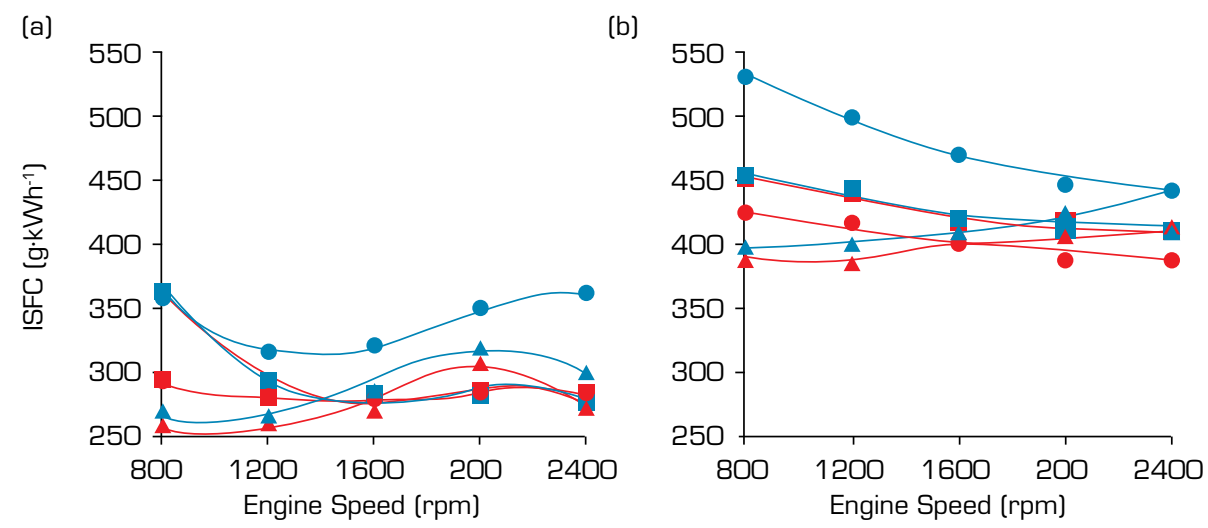

$32 \mathrm{~N} \cdot \mathrm{mL}^{-1}$ without

compressor

$32 \mathrm{~N} \cdot \mathrm{mL}^{-1}$ with

compressor

$96 \mathrm{~N} \cdot \mathrm{mL}^{-1}$ without

compressor

4 $96 \mathrm{~N} \cdot \mathrm{mL}^{-1}$ with

compressor

$160 \mathrm{~N} \cdot \mathrm{mL}^{-1}$ without

compressor

$160 \mathrm{~N} \cdot \mathrm{mL}^{-1}$ with
compressor

Figure 4. Specific fuel consumption for (a) gasoline and (b) ethanol. 
Figure 5 shows the specific power for the different engine speeds and loads tested. The maximum specific power of $40 \mathrm{~kW} / \mathrm{L}$ was set for both fuels tested. This resulted from a compromise between specific fuel consumption and supercharger power consumption, although higher power output could be obtained at the cost of lower overall engine efficiency. According to Fig. 4 , in this condition, the specific fuel consumption of ethanol was just below $400 \mathrm{~g} / \mathrm{kWh}$ and of gasoline it was around $270 \mathrm{~g} / \mathrm{kWh}$.

Taking as an example, the EMB-203 aircraft engine, Lycoming IO-540-K1J5, naturally aspirated and four-stroke cycle. This engine develops a power output of $238 \mathrm{~kW}$ at $2700 \mathrm{rpm}$ from a swept volume of $8.874 \mathrm{dm}^{3}$ and a compression ratio of $8.7: 1$, resulting in a specific power output of $26 \mathrm{~kW} / \mathrm{L}$. The efficiency of this engine is around $28.5 \%$ when operating with AvGas (Lycoming 2006). In this context, although both engine models do not require a reduction drive in the propeller connection, the four-stroke operation requires a larger number of cylinders and a larger displacement and consequently a heavier and bulker engine.

The 912 series engine from the manufacturer Rotax, widely used in ultralight, small and experimental aircraft, is a naturally aspirated four-stroke cycle model with four cylinders, swept volume of $1.352 \mathrm{dm}^{3}$ and compression ratio of 11:1 (Rotax, 2010). It has a power of $40 \mathrm{~kW} / \mathrm{L}$ at a speed above $4000 \mathrm{rpm}$ with a specific torque of approximately $90 \mathrm{Nm} / \mathrm{L}$. This model, despite having a smaller swept volume in relation to the previous comparison, indicates the need for a reduction drive since the rotation is too high for direct propeller operation, which adds weight and complexity to the system.

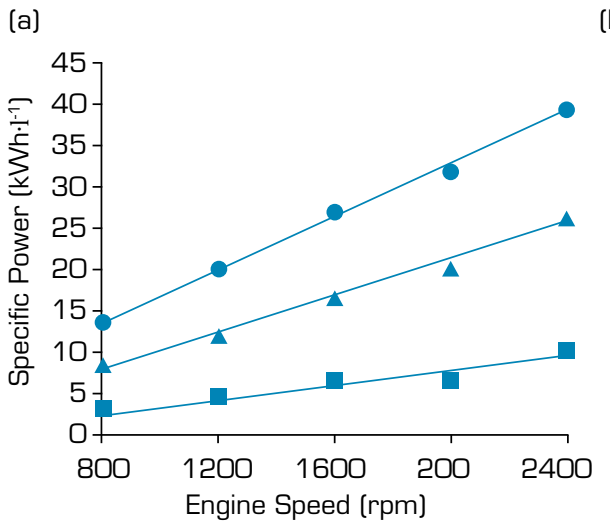

(b)

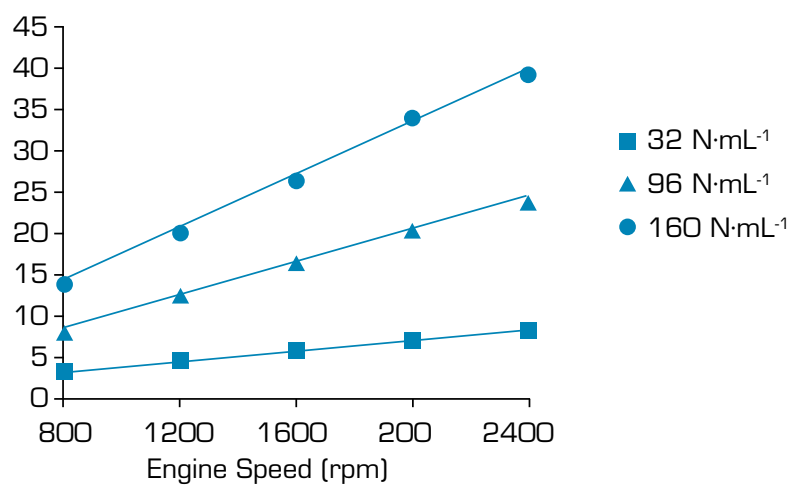

Figure 5. Specific power for (a) gasoline and (b) ethanol.

Figure 6 shows the ignition advance set for each engine speed and load value seeking minimum spark advance for best torque (MBT). It was seen that a greater advance in ignition was achieved for ethanol and the MBT condition was reached for the three load values. For gasoline, the ignition advance was limited by knocking combustion. This is a result of the greater resistance to detonation given by the higher octane number of ethanol (109 RON) compared to European gasoline (95 RON), besides ethanol higher latent heat of vaporization which reduces the in-cylinder temperature at the onset of combustion. The spark timings for gasoline were retarded at higher engine speeds due to the larger amount of hot in-cylinder gas trapped, which induced knock. On the other hand, ethanol demonstrated regular ignition timings despite of two speed conditions at the minimum load tested. This was a result of combustion instabilities as it can be found elsewhere (Dalla Nora et al. 2018).

Figure 7 shows the maximum pressures in the cylinder. The values observed are in the range between 2 and $6 \mathrm{MPa}$ for both fuels. In the case of gasoline, there are significantly lower pressure values above $1600 \mathrm{rpm}$, what is due to the knocking limitation. This knocking limitation forced a reduction in the ignition advance and, as a result, a peak pressure in the cylinder occurring later in the expansion cycle. In general, ethanol presented lower pressure values for the same load, which can be attributed to its higher cooling capacity, given its higher latent heat of vaporization than gasoline. 
(a)

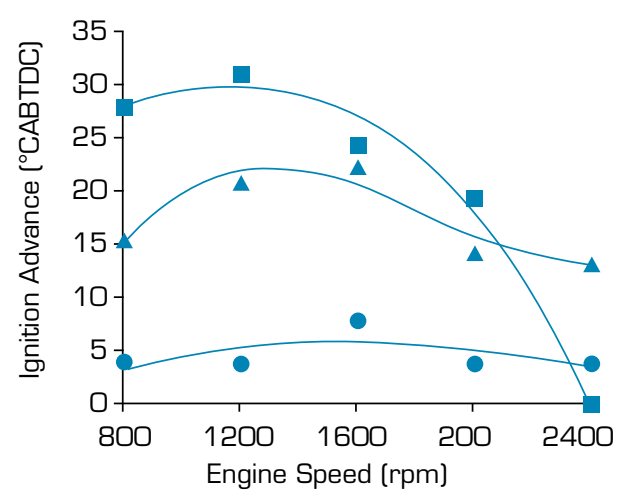

(b)

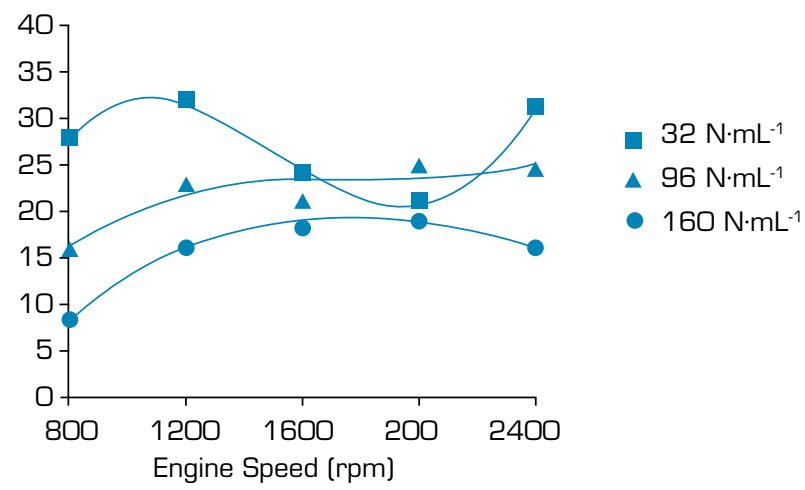

Figure 6. Ignition advance for (a) gasoline and (b) ethanol.

(a)

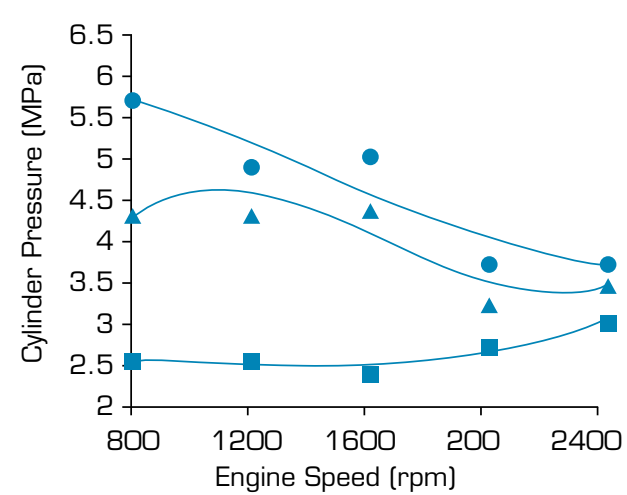

(b)

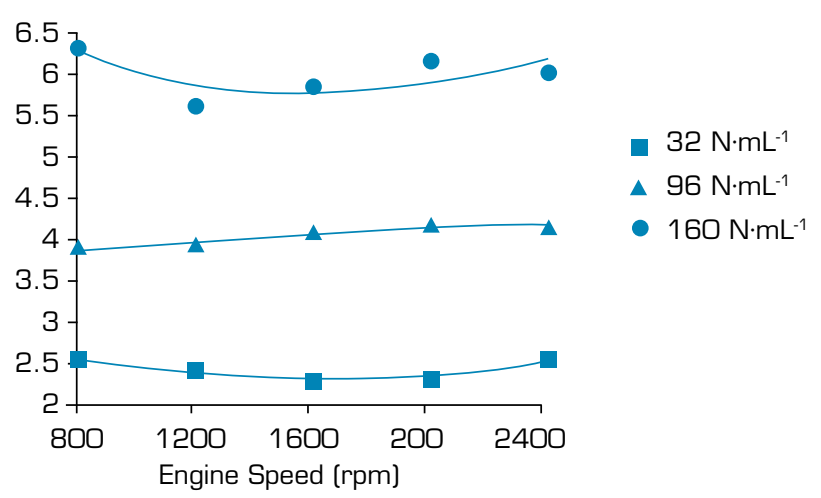

Figure 7. Maximum in-cylinder pressure for (a) gasoline and (b) ethanol.

The maximum pressure values in the cylinder are a significant advantage of the two-stroke cycle operation, since lower cylinder pressures allow to reduce structural stresses and to optimize combustion by ignition advancing around the MBT. In this way, a less robust engine can be achieved and, consequently, of lower weight and cost.

Figure 8 shows the inlet pressure values for each engine speed and load. For both gasoline and ethanol fuels, the highest pressures are presented together with the highest speeds and higher loads. The higher the engine speeds, the shorter was the absolute time available for gas exchanging and hence a higher intake pressure was required to displace the burned gases and keep the engine load. The lower values presented by ethanol at high load and high speed are also reflected in the higher indicated efficiency, which may be attributed to its oxygenated content. It should be noted that the observed intake pressure values could be easily achieved with air superchargers available on the market. Intake pressures usually found in the automotive market range from 110 to $250 \mathrm{kPa}$.

Figure 9 shows the exhaust gas temperature (EGT). The lowest temperature was found at minimum engine speed and maximum load at approximately $460 \mathrm{~K}$, while the highest temperature was achieved at maximum speed and maximum load at approximately $720 \mathrm{~K}$. At lower loads the exhaust temperature is essentially a function of the engine load, while at higher loads the temperature has a significant contribution of the effect of the air short circuiting due to higher intake pressures. It is possible to notice lower temperatures in ethanol operation when compared to gasoline, due to the higher thermal efficiency of the biofuel used. 
(a)

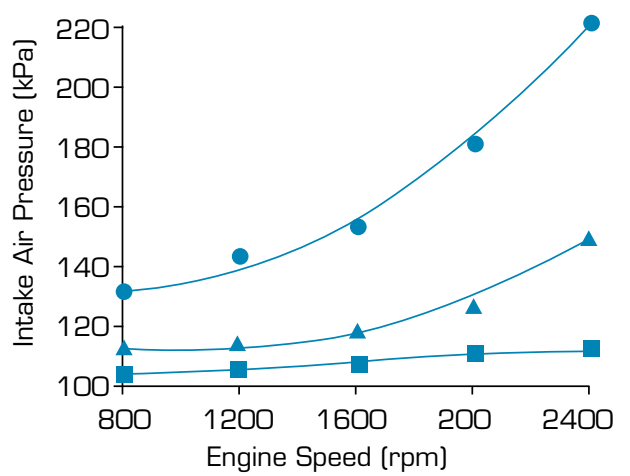

(b)

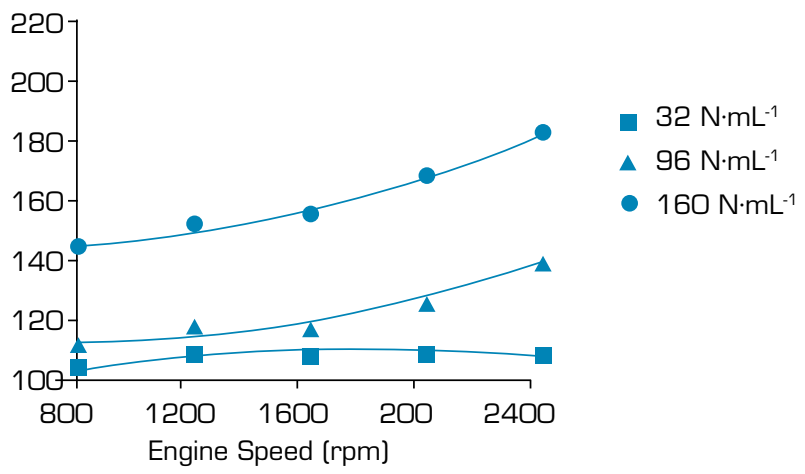

Figure 8. Intake air pressure for (a) gasoline and (b) ethanol.

(a)

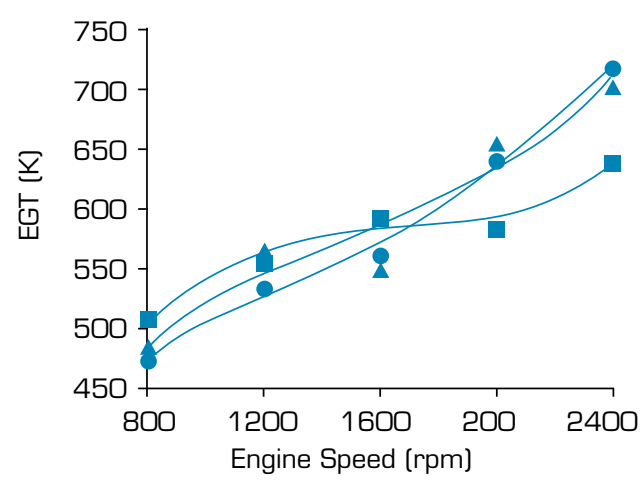

(b)

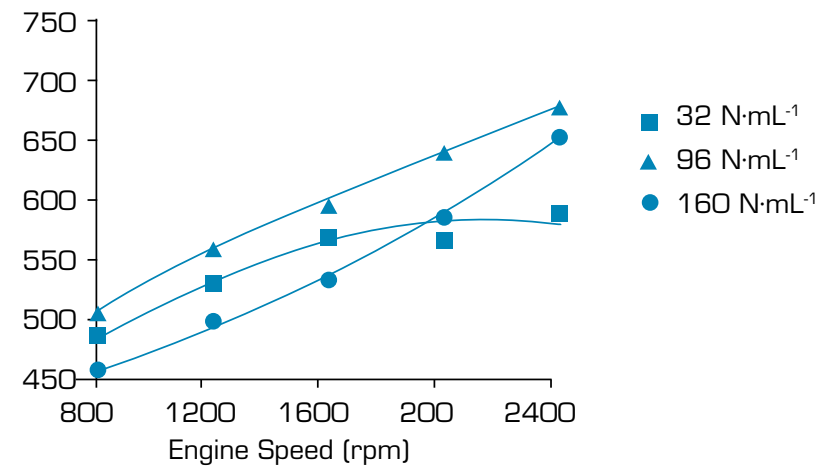

Figure 9. Exhaust gases temperature for (a) gasoline and (b) ethanol.

It is also interesting to observe a competing effect between heat generation rate due to higher engine speed and the air short circuit rate from intake to exhaust. This explains a higher temperature for the medium load of $96 \mathrm{Nm} / \mathrm{L}$, while at the higher load there was a cooling of the exhaust gas and the average temperature was the lowest observed between the loads tested.

The low exhaust temperatures observed, given the cooling effect of the exhaust gases by the portion of short-circuited air may present undesirable effects when turbochargers are applied since the energy available at the exhaust will be lower due to its lower temperature.

\section{CONCLUSIONS}

It could be observed that a four-stroke engine operating in the two-stroke cycle can provide superior power density allied with similar overall efficiency, while maintaining the reliability of a four-stroke cycle engine architecture.

Ethanol operation shows potential to replace AvGas, reducing the cost of operation and using a fuel from a renewable source without the addition of toxic components.

Also, the ethanol operation made it possible to reach the MBT without the occurrence of knocking combustion for maximum specific torque. The absence of knocking reduces the risk of engine failure in operation, in addition to allow an increase in engine efficiency since combustion occurs closer to the optimal point (MBT). Nevertheless, the lower heating value of ethanol results in higher specific consumption and hence a shorter flying range for the same loaded fuel mass, although the higher efficiency of ethanol operation may overcome part of this problem. 
The pressures in the cylinder, both for ethanol and gasoline, resulted in lower values compared to four-stroke cycle engines, allowing a less robust, lower cost and lighter engine.

The exhaust temperature found was lower than that observed in four-stroke engines due to the direct passage of part of the intake air, phenomena known as air short-circuiting.

Finally, the supercharging pressure required for engine operation can be easily reached by the technology present in the market for roots or centrifugal type blowers. However, the exhaust backpressure should receive attention when using turbochargers, since there must always be an intake-exhaust positive pressure ratio for the gas exchange to occur.

\section{AUTHOR'S CONTRIBUTIONS}

Conceptualization: Herrmann S; Dalla Nora M; Lanzanova TDM; Data curation: Dalla Nora M; Lanzanova TDM; Formal analysis: Herrmann S; Dalla Nora M; Investigation: Dalla Nora M; Methodology: Dalla Nora M; Lanzanova TDM; Software: Herrmann S; Resources: Dalla Nora M; Lanzanova TDM; Validation: Dalla Nora M; Lanzanova TDM; Writing - Original Draft Preparation: Herrmann S; Writing - Review \& Editing: Herrmann S; Dalla Nora M.

\section{DATA AVAILABILITY STATEMENT}

All the datasets were generated and analyzed during the current study.

\section{FUNDING}

Conselho Nacional de Desenvolvimento Científico e Tecnológico. Grant No GDE 245993/2012-6.

http://dx.doi.org/10.13039/501100003593

\section{ACKNOWLEDGMENTS}

The authors are grateful to the Organization Committee of II Congresso Aeroespacial Brasileiro, and to the Engines research group at Brunel University, London, particularly Professor Hua Zhao.

\section{REFERENCES}

[NAAA] National Agricultural Aviation Association (2019) Industry facts. [accessed Jun 30 2019]. https://www.agaviation.org/ industryfacts

Dalla Nora M, Lanzanova TDM, Zhao H (2016) Effects of valve timing, valve lift and exhaust backpressure on performance and gas exchanging of a two-stroke GDI engine with overhead valves. Energy Convers Manag 123:71-83. https://doi.org/10.1016/j. enconman.2016.05.059

Dalla Nora M, Lanzanova TDM, Zhao (2018) Investigation of performance and combustion characteristics of a four-valve supercharged two-stroke DI engine fueled with gasoline and ethanol. Fuel 227:401-411. https://doi.org/10.1016/j.fuel.2018.04.078 
Duret P, Moreau J-F (1990) Reduction of pollutant emissions of the IAPAC two-stroke engine with compressed air assisted fuel injection. Paper presented International Congress and Exposition. SAE Technical Paper Series; Detroit, Michigan, United States. https://doi.org/10.4271/900801

Hausen RB (2011) Sistematização de conhecimento para o projeto de motor a etanol para aeronave agrícola (Master thesis). Santa Maria: Universidade Federal de Santa Maria. In Portuguese.

Homa JM (2013) Aeronaves e motores. São Paulo: ASA.

Hundleby GE (1990) Development of a poppet-valved two-stroke engine - the flagship concept. Paper presented International Congress and Exposition. SAE Technical Paper Series; Detroit, Michigan, United States. https://doi.org/10.4271/900802

Leighton S, Cebis M, Southern M, Ahem S (1994) The OCP small engine fuel injection system for future two-stroke marine engines. Paper presented International Off-highway \& Powerplant Congress \& Exposition. SAE Technical Paper Series; Milwaukee, Wisconsin, United States. https://doi.org/10.4271/941687

Lycoming (2006) Operator's manual Lycoming: O-540, IO-540 series. Williamsport: Lycoming.

Mhereb GA, Norder LAC (2018) Aviação agrícola no Brasil: contexto e caracterização. Confins 36. https://doi.org/10.4000/ confins. 13638

Nomura K, Nakamura N (1993) Development of a new two-stroke engine with poppet-valves: Toyota s-2 engine. A new generation of two-stroke engines for the future? (Ed. Duret P.). Paper presented International Seminar held at IFP. IFP; RueilMalmaison, France.

Parceria Agro (2019) Brasil tem segunda maior frota de aviões agrícolas do mundo. [accessed Jun 30 2019] http://www. agropecuariaparceria.com.br/noticias/2367-brasil-tem-segunda-maior-frota-de-avioes-agricolas-do-mundo

Reuters (2017) Participação do agronegócio no PIB é a maior em 13 anos, estima CNA. G1: Globo. [accessed Jun 30 2019]. https://g1.globo.com/economia/agronegocios/noticia/participacao-do-agronegocio-no-pib-e-a-maior-em-13-anos-estima-cna. ghtml

Rotax (2010) Operator’s Manual Rotax Engine Series 912. Rotax Aircraft Engine.

Santos JMF (2005) Aplicação aérea e terrestre: vantagens e limitações comparativas. Paper presented V Congresso Brasileiro de Algodão. CBA; Salvador, Bahia, Brazil.

Santos LCB, Almeida CA, Carpena L, et al. (2018) Aviação particular - sumário estatístico 2008-2017. Centro de Investigação e Prevenção de Acidentes Aeronáuticos (CENIPA). Brasília, Distrito Federal, Brazil.

Sato K, Ukawa H, Nakano M (1992) A two-stroke cycle gasoline engine with poppet valves in the cylinder head - Part II. Paper presented International Congress and Exposition. SAE Technical Paper Series; Detroit, Michigan, United States. https://doi. org/10.4271/920780

Zhang Y, Zhao H, Ojapah M, Cairns A (2013) CAI combustion of gasoline and its mixture with ethanol in a 2-stroke poppet valve DI gasoline engine. Fuel 109(8):661-668. https://doi.org/10.1016/j.fuel.2013.03.002 